\title{
Um olhar sobre a relação entre sujeitos e meios técnicos: O público como construção social mediada
}

Looking at the relationship between subjects and technical means:

The audience as mediated social construction

\author{
Rafael Goffinet de Almeida \\ Instituto de Arquitetura e Urbanismo, \\ Universidade de São Paulo \\ rafael.goffinet.almeida@usp.br \\ Fábio Lopes Souza Santos \\ Instituto de Arquitetura e Urbanismo, \\ Universidade de São Paulo \\ sotosantos@uol.com.br
}

\begin{abstract} his/her condition as audience, observer, spectator or user.

\section{A prática artística como campo de investigação e crítica: do 'objeto contemplativo' à (auto)percepção do público}

This article analyses some of the proposals produced in the late 1970's by the American contemporary artist Dan Graham, in which he uses technical means to investigate the audience's perception and behavior. The questions raised highlight reciprocity phenomena and identity constructions - factors that affect our experience and behavior in contemporary cities daily life. All of these issues derive from Graham's investigations of the main information and communication technologies (media) produced at that time, and which continue to offer reflections on current relationship between technical means and the subject - that is,
Uma das questões centrais inauguradas pela produção da arte contemporânea, desde a década de 1960, foi a atenção cada vez maior dedicada às diversas dimensões (físicas e discursivas) que constituíam o "objeto" de arte (KWON, 2004). Uma mudança na prática artística que se concretizou a partir dos questionamentos sobre as convenções que até então regiam a produção e a exibição das artes plásticas. Denominada como Crítica Institucional, esta vertente de produção reuniu uma geração de artistas em torno da crítica ao estatuto do objeto isolado e protegido dentro do sistema artístico, e também em torno do desafio de repensar novas formas de produção e de inserção social para a arte.

Neste cenário, encontramos a produção do artista norteamericano Dan Graham, cuja contribuição para este processo de rompimento e abertura das práticas artísticas remete à atenção para a percepção e o comportamento do "público", dentro e fora dos limites do "cubo branco" (O'DOHERTY, 2007).

Como o artista demonstra através de suas propostas artísticas e de seus escritos, a tarefa da crítica aos espaços, aos discursos e às práticas institucionais da arte deveria enfocar também a influência que todas estas instancias do sistema artístico exerce sobre a experiência individual e coletiva de seus observadores - ou seja, o público. E, indo além em sua própria crítica, Graham percebeu como os mesmos fatores que levavam os objetos, os espaços e os discursos da arte a instigarem certos tipos de comportamentos sociais, eram possíveis de serem investigados também em relação a outros objetos e espaços aparentemente banais presentes no cotidiano das cidades contemporâneas.

Estes aspectos tornam-se mais claros se, em um primeiro momento, recorrermos aos comentários de Dan Graham sobre o conjunto de trabalhos de Dan Flavin utilizando tubos de iluminação fluorescentes. Remetendo à crítica sobre o vínculo entre os "objetos tridimensionais" do Minimalismo e os espaços expositivos, as análises escritas por Graham sobre a produção de "luminárias" de Flavin - presentes em "Art in relation to Architecture. Architecture in relation to Art" (1979), "My Works for Magazine Pages" (1981) e "Art as Design/Design as Art" (1986) - descrevem a curiosa descoberta por parte daquele que foi considerado um dos principais nomes da arte minimalista sobre a função exercida pela arquitetura do "cubo branco" em relação à apresentação e à recepção dos próprios trabalhos. De acordo com Graham:

"Que o trabalho fosse equiparado ao conteúdo arquitetônico tendia a fazê-lo mais literal; tanto o invólucro arquitetônico como a obra contida nele estavam pensados para serem vistos como neutros e objetivamente factuais, quer dizer, como simples materiais. A galeria funcionava, literalmente, como parte da arte. A obra de um artista desse período, as instalações de luzes fluorescentes de Dan Flavin 
(ainda que nem sempre seu trabalho posterior), examinava como os elementos arquitetônicos funcionais do interior da galeria prescreviam o significado do marco arquitetônico" (GRAHAM in WALLIS, 2008, p. XXIX, tradução nossa).

Ainda que muitos dos artistas minimalistas continuassem apostando na construção de seus objetos somente a partir de um vocabulário formal baseado em relações internas (proporção, tamanho, distâncias, materialidades, etc.), Graham reconhecia que a própria leitura de seus trabalhos era também resultado de fatores externos. Mais do que isso, a natureza da percepção pretendida por estes artistas derivava das condições que o espaço expositivo historicamente imprimiu sobre a atividade do público.

Não por menos, a crítica ao objeto contemplativo tornou-se uma questão decisiva na trajetória de Dan Graham, direcionando sua crítica às convenções ainda presentes na produção de seus colegas para as convenções que determinam o estatuto do objeto artístico. Através da exploração de novos suportes e de novas concepções de trabalho, o artista conquistava imensa liberdade estética e inaugurava um novo campo questões para a arte. É a partir desta perspectiva que se torna possível compreender intervenções sobre o suporte da mídia impressa das revistas - Homes for America (1965) e Income (Outflow) Piece (1969) -, a longa pesquisa utilizando meios técnicos como o vídeo, o filme e o espelho - Sunset to Sunrise (1969) e Roll (1970) -, a inclusão do corpo como parte de suas investigações Performer/Audience/Mirror (1975) e Public Space/Two Audiences (1976) -, além do interesse sobre diversos dispositivos virtuais e espaciais presentes na cidade - Video Piece for a Shop Window in na Arcade (1976) e Video Piece Outside Home (1978-96). Essas mesmas questões reaparecem em sua produção de textos, artigos e ensaios.

Entre estes conjuntos de trabalho aparentemente dispersos, Graham construía uma investigação sobre a relação entre o objeto, seus observadores e o espaço em que estavam inseridos, culminando na sua crítica, bastante original, sobre os mecanismos de constituição do público. Para o artista, uma vez que o objeto contemplativo ativa (e influencia) uma certa forma de subjetividade, romper com esta condição do objeto permitiria abrir outras possibilidades de experiência sensível. Este é precisamente o prisma através do qual viria, mais tarde, investigar os mesmos efeitos sobre o público observados em relação aos espaços protegidos da arte também em outras situações constitutivas do cotidiano urbano.

Perseguindo estes novos objetivos, veremos o artista pesquisando outros suportes artísticos, conforme manifestado em sua produção realizadas ao longo da década de 1970. Seu conjunto de vídeo-projeções, performances e instalações com o uso do vidro, vídeo e espelho com intensa utilização de meios técnicos de reprodução audiovisual, tem como objetivo reproduzir corpos em movimento, explorar pontos de vista invertidos ou inusitados sobre ações ocorridas no espaço e no tempo presentes. Através destes novos "meios", Graham buscava operar no interior do campo de representação, pondo em questão a relação entre o público e o objeto, em outras palavras, entre sujeitos e meios técnicos.

Através de performances, videoinstalações e propostas de intervenções espaciais, como, respectivamente, Performance/Audience/Mirror (1975), Public Space/Two Audiences (1976), Video Piece for a Shop Window in an Arcade (1976) e Video Piece Outside Home (1976-96), Graham tencionou o desempenho técnico e social de sistemas de exibição, visualização, produção e circulação de informações habituais, enfocando e explicitando muitas das relações intersubjetivas dos sujeitos-observadores diante destes sistemas.

A análise destes trabalhos lança luz sobre fenômenos de reciprocidade e de construções de identidade neles implicados. Fatores que teriam a capacidade de pautar nossa experiência e comportamento em diversas situações cotidianas nas cidades contemporâneas. Todas estas questões são frutos da leitura realizada pelo artista sobre as principais tecnologias de informação produzidas neste período, e que podem gerar novas reflexões inclusive sobre as relações possíveis entre sujeitos e novos meios técnicos, suas condições enquanto público, audiência, espectador ou usuário.

Afim de compreender estas questões, o artigo explora uma divisão latente no conjunto de trabalhos aqui reunidos. Por um lado, Performer/Audience/Mirror e Public Space/Two Audiences representam o momento em que Graham explora a presença física e imediata do público no interior das galerias e museus para ativar sua autoconsciência - em suas palavras, fazer com que "se percebessem no lugar de perceber o objeto de arte". Por outro, o conjunto definido por Video Piece for a Shop Window e Video Piece Outside Home configuram um aprofundamento desta pesquisa. Se as primeiras propostas eram realizadas em situações onde a presença dos meios técnicos era evidente (o sistema plateia-palco para um; o espaço expositivo para outro), desta vez o artista direciona sua atenção para situações aparentemente banais do cotidiano urbano (como as galerias comerciais ou a intimidade do lar), quando a interferência dos meios técnicos não é tão legível (as vitrines e o sistema de vigilância e de TV à cabo).

Um terceiro conjunto de trabalhos, constituído por seus escritos, complementam estas análises. Dean Martin/Entertaimente as Theater (1969) e Essay on Video, Architecture and Television (1978) e The End of Liberalism (1981) reúnem as discussões realizadas pelo artista e as principais influências teóricas que irão informar sua produção - como o mecanismo de representação ativado por conteúdos midiáticos, os conceitos da psicanálise observados em autores como Jacques Lacan, e o impacto de novas tecnologias de captura e exibição de imagens sobre a organização espacial.

Ao final, o que aqui se pretende demonstrar é como as pesquisas de Dan Graham expõem o funcionamento destes meios através de experiências concretas direcionadas a seu público, dando especial atenção para as rupturas e alterações 
provocadas pelo artista capazes de revelar um fenômeno oculto: a própria constituição do público.

\section{Performance/Audience/Mirror e Public Space/Two Audiences: o enfoque sobre a percepção e o comportamento do público.}

Para aprofundarmos a discussão acerca da investigação do artista sobre como o "cubo branco" dos museus e galerias "produzem" seu próprio público e como esta investigação permitiu deslocar sua atenção para outros espaços e outros dispositivos podemos tomar como ponto de partida a influência exercida pelo marco de referência definido pelo contexto arquitetônico sobre a atividade do observador. Grosso modo, as convenções que historicamente pautaram tanto o estatuto do objeto de artístico quanto as relações estabelecidas com seu público também definem, no interior deste processo, padrões de experiência subjetiva e de comportamento social.

Esta é a problemática a que Graham irá se debruçar ao longo da década de 1970, quando explora formas de representação espaço-temporal através de sistemas de vídeomonitoramento, muitas vezes combinadas com o reflexo de espelhos e paredes de vidro. Performer/Audience/Mirror e Public Sapce/Two Audiences produzidos entre 1975 e 1976 configuram um estágio de amadurecimento de suas pesquisas. Depois de uma série de trabalhos experimentando vídeo-projeções, lançando para o público diferentes pontos de vista que relativizavam a percepção sobre um acontecimento filmado a priori ou em tempo real, neste momento o artista desenvolve sistemas de exibição/percepção para redefinir o desempenho convencional de dispositivos espaciais reconhecidos pelo público, como é o caso da divisão plateia/palco e do próprio espaço expositivo.

Em relação à performance Performer/Audience/Mirror, o público presente encontra a figura do artista/performer dominando o palco de um auditório que separava a plateia de um enorme espelho posicionado às suas costas. Na primeira parte da duração do "espetáculo", o performer cativa as atenções individuais ao descrever a si próprio e seus movimentos - uma atividade perceptiva considerada habitual e já naturalizada pelos observadores. Porém, em seguida, faz com que a atenção da plateia se volte para si mesma, ao começar a descrever algumas das pessoas presentes. $\mathrm{Na}$ última parte, o performer volta-se para o espelho e sobrepõe às descrições do público ali refletido a sua própria imagem. Através dessa articulação ente espaços e imagens (visuais e orais), Graham colocava a (auto)percepção do público em constante alteração, sendo construída e reconstruída, confrontando-se com 0 mecanismo de construção de subjetividade imposto ao mesmo tempo pelo espaço cênico e pelo comportamento passivo que geralmente se assume quando cumpre seu "papel" de plateia, espectador, audiência ou observador. Ao reencontrar sua própria presença através do reflexo e da narração do performer, o sujeito observador também se reconhece enquanto parte de um grupo socialmente definido: o público da performance.

Neste sentido, propostas como Performer/Audience/Mirror e representam outras formas e outros processos de inserção dentro de uma realidade constituída por camadas de complexos significados simbólicos, políticos e ideológicos presentes não apenas no mundo da arte, mas também fora dele. De acordo com Brian Wallis, Graham investigava a "nova forma de cumplicidade sofisticada, de uma pseudo-intimidade consciente" que está sendo explorada por diversos meios, agentes e espaços do cotidiano urbano contemporâneo como as os espetáculos musicais e também as imagens publicitarias, os programas televisivos, os filmes, entre outros produtos e manifestações culturais de massa.

Neste ponto, encontramos considerações valiosas do artista em seu texto "The End of Liberalism "(1981), principalmente quando discute algumas implicações mais amplas das pesquisas estéticas promovidas pelo Expressionismo Abstrato iniciadas em 1950. Se por um lado, o artista aproximou esta produção de arte de ponta norte-americana com o aperfeiçoamento dos veículos de comunicação de massa - fornecendo um campo de experimentação bastante fértil para a produção de imagens espetaculares -, de outro, o texto também constrói uma reflexão crítica sobre os significados ideológicos implícitos no modo de percepção que essas imagens ativavam. Para Graham, o Expressionismo Abstrato desenvolveu uma modalidade própria de discurso, responsável por estabelecer uma relação subjetiva peculiar entre obras, artistas e seu público. Através da inauguração de novas técnicas de pintura, como a action painting de Jackson Pollock, transferindo a ação intersubjetiva do artista para a superfície das telas, agora de proporções "heroicas" e sempre através de formas abstratas, estes artistas estavam provocando o que Graham irá se referir como uma "abstração subjetiva", isto é, um tipo de impacto visual que detém o público em um estado de contemplação capaz de eliminar a percepção de todo o contexto a sua volta, fixando-o no ato e no momento estrito de sua relação com a obra. O que teria inaugurado uma série de implicações de ordem social: Graham reconhece no estado contemplativo proporcionado por estas pinturas o mesmo fascínio despertado pelos produtos e ações da indústria cultural.

Citando o influente artigo de Laura Mulvey, "O prazer visual e o cinema narrativo", Graham afirma que "esta nova situação gerou um sujeito alienado, desgarrado em sua memória imaginária por um sentido de perda, pelo terror de uma falta de potencial de sua fantasia" (MULVEY apud GRAHAM, 2008).

De fato, o apelo visual e simbólico presente nos elementos mais banais do cotidiano das grandes cidades, como os cartazes e letreiros, as embalagens dos produtos que consumimos, as revistas que lemos e também o conteúdo televisivo que assistimos diariamente parecem ter recriado a estrutura subjetiva da "pintura heroica" através de imagens espetaculares desprovidas de significados para além do prazer visual imediato. Neste sentido, o que está em jogo e o que se mostrara ser também uma questão central para o 
artista são as formas de ativação da percepção desse novo público e de seu estado de consciência, como uma clara tentativa de compreender a influência que o s diversos meios e dispositivos de comunicação inaugurados na sociedade de massas exercem sobre ele. Por outro lado, essa constatação leva o artista à busca de situações em que seu público seja levado a confrontar-se criticamente com estes meios e seus modos de subjetividade.

A referência a Laura Mulvey, não é fortuita. Graham amplifica a ideia da autora de que estava em curso a construção de uma estrutura linguística capaz de manipular "hábil e satisfatoriamente" o prazer visual dos observadores - seja a narrativa do cinema, a "abstração subjetiva" dos expressionistas ou a comunicação visual das peças publicitarias. Em verdade, a influência das teorias críticas cinematográficas que se observa nas propostas e textos de Graham reflete a importância que o campo do cinema exerceu sobre a problematização da atividade do espectador. E, na esteira dos questionamentos desenvolvidos por Mulvey, convém lembrar o que Ismail Xavier, importante teórico e critico brasileiro de cinema, naquele mesmo período já alertava: para o autor, se tornava cada vez mais urgente discutir a relação de "identificação" entre os espectadores e os conteúdos transmitidos pelos produtos visuais, como uma forma de "acentuar as ações do aparato que constrói o olhar" - podendo atuar como uma "ponte" ou como uma "interposição" (XAVIER, 1988).

Este é precisamente o conjunto de questionamentos disparados pelo artista a partir do texto "Dean Martin/Entertaiment as Theater" (1969). Nele, Graham analisa o programa de TV "Dean Martin Show", de grande repercussão naquele momento, lançando aquelas que seriam as principais questões de suas pesquisas sobre as dinâmicas que presidem o olhar e a recepção dos produtos culturais, bem como os mecanismos de envolvimento do público (no caso, do telespectador) estabelecidos pelo programa.

Logo de início, o artista faz uma descrição de um episódio especifico do "show", analisando o comportamento de seu apresentador: uma figura embriagada, trapalhona, porém elegantemente trajada e divertida. A performance da "personagem" produzida por Dean Martin, os breves e cômicos esquetes que vão desencadeando o "show", além de vários outros recursos que expõem o próprio aparato televisivo representavam uma inovação frente ao decoro formal dominante nos meios televisivos.

A aparente "informalidade" presente em Dean Martin Show é comparada por Graham com pesquisas estéticas essenciais para a arte contemporânea, como a dramaturgia de Bertolt Brecht, a produção de vídeos de Andy Warhol e o cinema de Jean-Luc Godard. Entre todos estes autores, Graham destaca os mecanismos pelos quais buscavam revelar para seu espectador o funcionamento do "espetáculo" (teatral ou cinematográfico) através de diferentes recursos que pareciam aproxima-lo da própria feitura, redefinindo politicamente seu posicionamento em relação aquilo que assistia.
A princípio, não está claro no texto se as estratégias identificadas por Graham no programa de Dan Martin funcionam para despertar a consciência de seus espectadores ou mesmo provocar algum impacto em sua condição de espectadores - mesmo citando Brecht, Warhol e Godard. Em verdade, Graham ter concentrava sua análise sobre as estruturas do show, objetivando tornar explicita a paradoxal relação de "intimidade" estabelecida entre público e o meio televiso. Uma relação destacada por Graham para lançar ao leitor a dúvida se ela não estaria provando um efeito a contrapelo, mais próxima as noções de cooptação da subjetividade dos espectadores através de artifícios como a "sedução", presente no olhar introspectivo, a "ingenuidade" e a "simpatia" da figura trapalhona e quase familiar do apresentador.

A razão por trás da linha argumentativa presente no texto somente é esclarecida quando, já ao final, Graham discorre sobre como a construção da personagem de Dean Martin fazia parte de uma tendência da comunicação televisiva (e que se estendia para outros produtos e veículos de massa). Ao expor como ator, neste universo fundamentalmente comercial, é esvaziado de uma personalidade real e autêntica, apresentando-se tão abstratamente como qualquer outro produto a venda, torna-se claro que o interesse principal de Graham está na investigação das contradições destas formas e mecanismos de representação, de comunicação e envolvimento do público. Graham finaliza o texto alertando que, diante de tais meios e seus mecanismos operacionais, espera-se de nós, espectadores, "respondermos com nossas ações mecanicamente condicionadas, através de nossa repetida exposição ao meio em que somos semi-participantes manipulados" (GRAHAM in WALLIS, 2008).

Trata-se, portanto, de uma reflexão sobre as então vigentes formas de "impactar" o público, ou ainda sobre como este é resultado de um processo de "subjetivação", quando sistemas intencionalmente agem na construção de subjetividades. Um problema que transitava, ainda que de maneira antitética, entre os domínios da arte e da "não-arte", mas que aos olhos de Graham parecem operar um princípio comum: o grau de proximidade estabelecido com o observador.

Este grau de envolvimento do público identificado no programa de Dean Martin ressoava em uma declaração do vocalista da banda The Who, citada por Graham: "os espectadores são sensíveis enquanto estão abertos aos meios" e o artista, tanto quanto o meio, "deve mover-se com eles em um mesmo plano" (WALLIS, 2008, p.70).

Neste sentido, podemos colocar as reflexões de Graham em uma perspectiva critica bastante precisa: "Dean Martin/Entertaiment as Theater" expõe o funcionamento dos mecanismos midiáticos que se encontram naturalizados (de difícil identificação, portanto) e que fazem de seu público reféns de sua mensagem e forma de representação. Além disso, suas análises sobre as propostas de Brecht, Warhol e Godard também reclamam a importância de insistir no rompimento com este estado de total recepção do observador diante das cenas, dos eventos ou imagens com que se defronta. 
É neste aspecto que Public Space/Two Audiences deve ser analisado, sobretudo porque dispões a figura do público como principal protagonista desta performance seminal na trajetória do artista. As suas consequências para a pesquisa e Dan Graham sobre a (auto)percepção do público são decisivas.

Produzida para a $37^{\mathrm{a}}$ Bienal de Veneza, Public Space/Two Audiences é reconhecida como um aperfeiçoamento das técnicas e dos procedimentos operados nas propostas anteriores, alcançando um grau de síntese formal que já havia se tornado uma característica marcante de sua produção (herança de sua relação com a produção do Minimalismo). Nesta proposta, o número de repartições e de dispositivos técnicos (planos de vidro e espelhos, câmeras de vigilância associados a monitores de vídeo) presentes em Time Delay Room ou Present Continuous Past (ambas de 1974) foi resumido a apenas duas salas retangulares, com acessos independentes e separadas por um plano de vidro espelhado - funcionando também como um isolante acústico. Em uma das salas, a parede localizada ao fundo, paralelamente a este plano, foi totalmente coberta com espelho. Do outro lado, a face da divisória de vidro apresentava um leve grau de reflexão, sobrepondo à visão da outra sala as imagens do que acontecia dentro dela.

As soluções encontradas, as relações intersubjetivas que elas provocam, reorientaram sua pesquisas, na medida em que a espacialização da (auto)consciência do público permitiu explorar não apenas os códigos do olhar e da percepção, como também os códigos (físicos e discursivos) do próprio espaço. Através de Public Space/Two Audiences, Graham adensou a investigação sobre a (auto)percepção com a investigação da natureza social do espaço: para além do enfoque sobre o funcionamento institucional da galeria de arte, pautando as formas de recepção e percepção dos objetos expostos, Graham aprofundava sua descoberta sobre a construção social da figura do público.

Uma primeira análise sobre este trabalho logo reconhece a crítica sobre o espaço institucional representado pela Bienal, o status do objeto artístico no interior deste circuito e como ele foi realizado buscando interferir nas disposições convencionais entre o objeto e o público. A proposta de Graham, como uma espécie de armadilha, confronta os visitantes da Bienal com a sua própria imagem e comportamento no lugar de contemplar um objeto em exposição. Graham reconhecia e se posicionava frente à ideia de que as exposições da Bienal de Veneza desempenhavam uma função análoga às "Feiras Internacionais", que reuniam empresas e mercadorias como representantes do poder de produção dos principais países ao redor do mundo. Os artistas ali presentes, bem como seus trabalhos, não estão muito distantes da representação cultural desempenhada pelas mercadorias. Conforme Graham se referiu mais tarde, o dispositivo do vidro, que intermedia a performance do público no interior da instalação, funciona como uma vitrine em que "a arte exposta é a própria galeria" (GRAHAM apud SALVIONI, 1990, p. 143).

A inversão sobre as disposições entre objeto de arte e seus espectadores direciona as experiências sobre os processos subjetivos do público não somente a partir do olhar, mas sobretudo através das divisões intersubjetivas que definem interior e exterior, público e privado, individualidade e coletividade. A repartição física do espaço implica uma série de divisões sociais que são estabelecidas no exato momento em que os visitantes da bienal ingressam as salas configuradas pela instalação. Estes visitantes são lançados em um circuito em que as relações de reciprocidade estão em um permanente estado de construção e desconstrução (entre os "microgrupos" sociais que integram 0 ambiente particionado). A experiência com esta instalação trouxe à tona o fato de que seu funcionamento dependia das condições provocadas pelos elementos que conformam o espaço. A uma certa altura, Graham se pergunta: "o que aconteceria se retirasse a parede branca [oposta à parede espelhada]" - a instalação, conclui, "se tornaria arquitetura" (GRAHAM apud COLOMINA et al., p.19).

De fato, uma das grandes descobertas do artista entre as reflexões construídas em seus textos e os questionamentos disparados em suas propostas artísticas foi ter recolocado a representação visual na ordem dos eventos temporais e espaciais, bem como de ter introduzido o corpo (tanto o do artista/performance como o do próprio público/observador) como um meio decisivo par as suas investigações. Resta ainda analisar este novo horizonte colocado pelo artista: a investigação dos parâmetros da percepção humana e suas relações ou implicações dentro do contexto cultural definido pelas transformações que organizam a experiência cotidiana na cidade contemporânea.

\section{Video Piece for a Shop Window e Video Piece Outside Home: o desempenho social dos meios técnicos.}

Se recorrermos ao texto "Essay on Video, Architecture and Television", escrito por Graham em 1978, podemos observar uma série de reflexões em relação aos efeitos perceptivos e sociais promovidos por elementos arquitetônicos, a relação entre revelar e esconder, visão e corpo, ou ainda entre o Funcionalismo arquitetônico e o Capitalismo. Através destas questões, o artista lança a perspectiva sobre os elementos arquitetônicos enquanto meios decisivos para a construção do espaço em um sentido social e culturalmente definido, permitindo indagações que cercam a tensão entre "códigos arquitetônicos versus códigos sociais" (GRAHAM in ALBERRO, 1999, p. 53).

À medida que a leitura avança os diferentes tópicos que compõem o texto - Film and vídeo: vídeo as presente-time; Centralization/de-centralization of information; The architectural code/the vídeo code; 'Public'/'private' codes; Conventions of the glass Window; The mirror image/the vídeo image; Mirrors and 'self'; Video feedback; The glass divider, light and social division; Glass used in shop windows/commodities in shop windows; Glass Buildings: corporate 'showcases' - constrói-se um claro movimento que conduz as observações das propriedades objetivas de cada 
suporte analisado (filme, vídeo, vidro e espelho) às suas dimensões sociais, culturais e políticas (controle de informação, convenções e divisões sociais do espaço). Além disso, outro importante aspecto da discussão construída por Graham neste texto é o fato de que esta correlação entre o desempenho técnico e social encontra respaldo em situações reais existentes na cidade (a vitrine de estabelecimentos comerciais e a fachada envidraçada dos edifícios corporativos).

Os dois últimos tópicos definidos por "O Uso do Vidro nas Vitrines / Mercadorias nas Vitrines" e "Construções de Vidro: 'Vitrines' das Corporações" resumem bem este raciocínio. Eles apontam para como uma ação objetiva, tal como a construção do dispositivo da vitrine ou da fachada envidraçada, guarda um significado subjetivo materializado por meio dos olhares e dos comportamentos dos observadores quando diante deles. De um lado, as disposições que a vitrine estabelece entre cada elemento envolvido no desempenho deste aparato arquitetônico (aí incluída o próprio observador, juntamente com sua imagem projetada sobre o pano de vidro que o separa da mercadoria exposta) respondem a uma função que marca as relações de troca e de consumo dominantes nas cidades contemporâneas. De outro, os efeitos óticos disparados pela reflexão e a dimensão do ego que define a confrontação da própria imagem, associada ao forte sentido social que a barreira física do vidro implica (ao separar corpos e espaços), intermedia a sua presença projetando em seu inconsciente um estado de ilusão em que a mercadoria exposta atinge uma condição de síntese de sua própria representação. Graham afirma que o pano de vidro utilizado como um dispositivo de vitrine comercial está "eficientemente empreendendo os desejos latentes do passante casual, para conferir um significado subjetivo pré-determinado sobre os bens que este 'objetivamente' coloca sobre o que está sendo visto" (GRAHAM in ALBERRO, 1999, p. 58).

A partir deste momento, a cidade e seus elementos constitutivos, tomados como meios técnicos e sociais, dominarão as propostas de Graham. Seu enfoque incide sobre como os mecanismos pelos quais os componentes, elementos, dispositivos e outros recursos arquitetônicos e/ou espaciais estão pautando a experiência cotidiana das cidades contemporâneas. Seguem, então, as propostas de intervenção sobre algumas situações explicitamente urbanas, uma abordagem crítica sobre séries de dispositivos arquitetônicos aparentemente banais que funcionam como verdadeiros dispositivos de subjetivação - produzindo diferentes públicos na cidade contemporânea.

Em trabalhos como Video Piece for Two Glass Buildings e Video Piece for Shop Windows in an Arcade (ambas de 1976) os suportes do vidro, do espelho e do vídeo. Sua estratégia concentrava-se em explicitar a forma como estes suportes atuam sobre a subjetividade do público (ou passante, usuário), buscando despertar a (auto)consciência sobre 0 funcionamento e os significados implícitos dos lugares em que estavam inseridos.
Video Piece for Two Glass Buildings consistia na instalação de espelhos como pano de fundo em salas de escritórios existentes em dois altos edifícios empresarias, dispostos frente a frente. Junto à abertura de cada sala, seriam também instaladas câmeras de vídeo associadas a monitores exibindo a cena captadas em tempo real. Em entrevista, Graham afirma que a partir desta intervenção as pessoas poderiam "ver os observadores se olhando como se vistos em um espelho, sendo observados por outras pessoas nos escritórios dos edifícios de vidro" (GRAHAM in COLOMINA et al, 2001, p. 15). Neste trabalho, Graham segue de perto os objetivos e procedimentos empregados em Public Space/Two Audiences, mas transplantando-os às condições urbanas. Novas questões afloram.

"Essay on Video, Architecture and Television" apresenta outro tópico dedicado a questões disparadas por esta intervenção: "A divisória de vidro, luz e divisão social". Graham começa com uma frase cortante, que sintetiza seu conteúdo: "O vidro das janelas aliena o sujeito do objeto" (GRAHAM in ALBERRO, 1999, p. 58). E contrasta a condição de quem observa com a de quem é observado: "A visão do observador defronte do plano de vidro é 'objetiva'; a do sujeito observado (e sua subjetividade) é ocultada" (GRAHAM in ALBERRO, 1999, p. 58). Essa assimetria de poder, pode ser parcialmente debitada às propriedades intrínsecas do material do vidro, uma vez que, de acordo com as análises do artista, sua refletividade produz um "signo" que é, simultaneamente, "a natureza da oposição entre os espaços e sua intersecção”. De fato, o vidro provoca uma separação física, mas ao mesmo tempo permite uma conexão visual e o desafio colocado pelo artista seria o de demonstrar as motivações sociais por detrás de sua utilização, seja nas fachadas envidraçadas dos edifícios corporativos ou mesmo nas vitrines de lojas.

Esta é a questão que também norteia a intervenção de Video Piece for Shop Windows in an Arcade. Análoga à anterior, a proposta de Graham pretendia ocupar as fachadas de duas lojas existentes em uma típica galeria comercial, dispostas frente a frente. Nas vitrines, previa-se a instalação de espelhos (ao fundo) e câmeras e monitores de vídeo (à frente, junto às mercadorias). Dessa maneira, o artista buscava intervir no processo subjetivo ativado pelo dispositivo da vitrine. Contrariando a estrutura ótica que projetaria o ego do observador sobre a mercadoria exposta, conforme discutido em "Essay on Video, Architecture and Television", através da articulação entre o sistema de vídeo e espelho com a configuração espacial das lojas, o "público" da galeria se depararia com a sobreposição de distintos planos de imagem: a imagem de seu próprio reflexo, a presença das mercadorias e com as diversas imagens refletidas a partir da fachada oposta juntamente com o vídeo da situação sendo exibido pelos monitores. O que acabaria por despertar alguns significados implícitos na própria condição da vitrine.

De acordo com o próprio artista, o plano de vidro que dá forma a este dispositivo funciona como o elemento mediador (e simbólico) de um estado de "alienação e incompletude" entre a mercadoria e a consciência do indivíduo/consumidor (PELZER in COLOMINA et al., p. 57). Neste sentido, as operações que realiza o revela enquanto elemento mediador 
e simbólico de um "estado de alienação e incompletude" entre mercadoria e a consciência do consumidor. (PELZER in COLOMINA et al., p. 57).

"Perante a vitrine, o comprador, seu sentido de 'eu', identificase não apenas com o objeto focado em sua visão, mas com o 'Sistema' que criou o dispositivo. A janela-vitrine, um dispositivo ótico de enquadramento, replica 0 espaço renascentista: enquadra uma vista determinada (determina uma vista), criando um ponto focal. Desta maneira, o olhar do comprador, seu foco, cria o valor. O 'eu' do comprador, desarmado, projetado no espaço, identifica-se com o objeto representado: sua 'auto-projeção', organiza significados ao redor do objeto enfocado; nele reencontra seu olhar centrado" (GRAHAM in ALBERRO, 1999, p. 57).

Neste aspecto, uma das questões centrais disparadas por este trabalho remete aos limites entre a esfera pública e a esfera privada (e íntima), configurando uma pesquisa particular dentro das propostas de Graham em relação ao desempenho social do espaço. Algo que ganha amplitude se analisarmos as questões presentes em Video Projection Outside Home, concebida em 1978 e realizada somente em 1996. Nesta proposta, Graham instala no exterior de uma típica residência suburbana, no jardim voltado para a rua, um enorme aparelho televisor que transmite em tempo real 0 conteúdo assistido pelos moradores.

Trata-se de uma exposição pública de algo praticado na intimidade do lar e, mais do que isso, de algo paradoxalmente identificado como íntimo. Graham demonstra como o dispositivo da televisão controla, de maneira centralizada, a produção e a circulação de conteúdos. Tal como escreve em "Essay on Video, Architecture and Television", a massificação e a expansão do sistema de televisão representam "uma imposição assim ética da informação pelo capital" através da instalação de verdadeiros terminais que decidem o que e como será visto (e consumido) no interior das residências - 0 habitat da intimidade. (GRAHAM in ALBERRO, 1999, p. 52).

Esta percepção do artista amplifica a inserção de sua crítica e a experiência proporcionada pela contemplação de uma intimidade que é ao mesmo tempo produzida comercialmente e pessoalmente partilhada, refletindo uma relação paradoxal entre as esferas "pública" e "privada" na vida cotidiana. Através de sua proposta, Graham questiona como dispositivos aparentemente banais, como o caso da televisão, teriam o poder de construir laços afetivos e de identificação pessoal com estes conteúdos, de maneira que, ao atentarmos para os programas e anúncios "expostos" pela intervenção de Video Piece Outside Home, questionamos nossa própria identidade ao dar-nos conta de que fatores exteriores estariam pautando nossa experiência intima, isto é, daquilo que nos é tido como verdadeiro e real.

\section{O fenômeno oculto: a constituição de "públicos".}

O alcance da crítica presente na proposta de intervenção de Dan Graham sobre a relação de poder implicada através do sistema de televisão à cabo (bem como de outros sistemas de telecomunicação) pode ser amplificado se observada na perspectiva das formas de controle social discutidas por dois expoentes do pensamento contemporâneo: o "poder disciplinar" de Michel Foucault e a "sociedade de controle" de Gilles Deleuze e Félix Guattari. Em um primeiro momento, a ideia de um poder centralizador, expressado no controle de produção televisiva e que se converteria em padrões de comportamento social, nos levaria à imagem do Panóptico de Bentham - expressão máxima do controle que se estende ao nível dos corpos individuais, segundo Foucault (FOUCAULT, 2006). Porém, o poder (ou sua forma de controle) retratado em Video Piece Outside Home não é aquele da sensação de estar sendo o tempo todo vigiado por uma entidade disciplinadora que permanece despersonalizada, no alto e ao centro da torre de comando. Pelo contrário, no contexto das novas formas de comunicação, o controle torna-se coletivizado e parece assumir a forma rizomática trabalhada por Deleuze e Guattari (2011): o controle social, agora, está baseado na livre escolha de uma possibilidade (ou da combinatória de possibilidades) definida a priori e oferecida pela indústria de massa. Dessa maneira, o indivíduo interioriza essa escolha como constituinte de sua própria identidade, daí o constrangimento sentido na exposição de seu "eu" interior.

Ao final e ao cabo, as pesquisas de Graham acerca dos processos de recepção, percepção e comportamento do público colocam em questão como formas de conteúdos projetados e "pré-fabricados" acabam influenciando a construção da vida íntima, da subjetividade e das relações afetivas dos (e entre os) indivíduos. Dessa maneira, também lançam luz sobre os códigos do olhar, os mecanismos intersubjetivos e as divisões sócio-espaciais envolvidas nessa construção.

Vistos em conjunto, os diversos meios técnicos trabalhados pelo artista (espaço expositivo, plateia/palco, ambientes temporários, vitrines, fachadas envidraçadas, câmeras de vigilância, sistemas de televisão à cabo e de tantos outros dispositivos que poderiam estender a esteira de sua crítica), explicita 0 fato de que eles configuram grupos sociais específicos, com expectativas, subjetividades e padrões de comportamento bem definidos. Como visto, se há algum constrangimento em ter-se a intimidade exposta e devassada a partir da exposição pública de conteúdos midiáticos consumidos no interior da residência, ou se este sentimento acontece ao recobrar-se a consciência do próprio corpo e da própria presença diante de uma performance, de uma pintura, de um espetáculo musical ou de uma projeção de um filme, esse constrangimento se dá tanto ao perceber sua própria subjetividade e afetividade projetada para fora do domínio convencionalmente privado (do interior da residência ou da própria intimidade), quanto à tomada de consciência de que estas mesmas formas de intimidade são constituídas exteriormente, isto é, a partir de agentes e meios convencionalmente entendidos como "públicos" (como as emissoras de televisão e o sistema de transmissão à cabo, os inúmeros veículos de comunicação de massa, suas incessantes mensagens e discursos publicitários, o marco arquitetônico das galerias e museu e tantos outros espaços encontrados na cidade). 
Além disso, embora seus trabalhos estejam ancorados em um momento anterior às novas tecnologias, como os atuais sistemas de redes digitais, as questões identificadas em sua crítica sobre a relação entre sujeitos e meios técnicos constroem um quadro de questões mais estruturais através do qual podemos projetar novas reflexões, além de avaliar as relações estabelecidas por estas novas tecnologias com os questionamentos levantados por uma produção artística situada em um momento histórico que as precederam.

Dentre estas questões, podemos relacionar a esta altura: o tipo de cumplicidade sofisticada a que estamos atualmente sendo submetidos, ou o grau de proximidade que os novos meios estão estabelecendo; a necessária avaliação sobre nossa condição de "usuários", sobretudo quando uma das principais novidades tecnológicas é o aprofundamento de mecanismos e sistemas baseados da interação e na participação; os novos padrões de comportamento e os dispositivos (físicos ou virtuais) através do quais eles são construídos; e, por fim, quais as estratégias que atualmente são capazes de explicitar todos estes fatores e despertar nossa (auto)consciência sobre seus desempenhos técnicos e sociais.

\section{Referências}

Alberro, A. (Ed.). (1999). Two-Way Mirror Power: Selected
Writings by Dan Graham on his Art. Boston: The MIT Press.

Colomina, B.; Frank, M.; Pelzer, B. (2001). Dan Graham. New York: Phaidon.

Deleuze, G.; Guatarri, F. (2011). Mil Platôs. São Paulo: Editora 34.

Foucault, M. (2006). O poder psiquiátrico: curso dado no College de France (1973-1974). São Paulo: Martins Fonte.

Graham, D. (2009). El arte con relación a la arquitectura. La arquitectura com relación al arte. Barcelona: Gustavo Gili.

Graham, D. (1999). Essay on Video, Architecture and Television. In ALBERRO, A. (Ed.), Two-Way Mirror Power: Selected

Writings by Dan Graham on his Art (pp. 52-61). Boston: The MIT Press.

Graham, D. (2008). Dean Martin/Entertainmetn as Theater. In WALLIS, A. (Ed.), Rock, mi religion (pp. 64-75). Cidade do México: Alias Editorial.

Graham, D. (2008). El fin del Liberalismo. In WALLIS, A. (Ed.), Rock, mi religion (pp. 79-91). Cidade do México: Alias Editorial.

Kwon, M. (2004). One place after another: Site-Specific Art and Locational Identity. Boston: The MIT Press.

O’Doherty, B. (2007). No interior do Cubo Branco. São Paulo: Martins Fontes, 2007. 